Open Access

\title{
Predictors of self-injury cessation and subsequent psychological growth: results of a probability sample survey of students in eight universities and colleges
}

\author{
Janis Whitlock ${ }^{1 *}$, Kemar Prussien ${ }^{2}$ and Celeste Pietrusza ${ }^{3}$
}

\begin{abstract}
Background: Factors affecting non-suicidal self-injury cessation are poorly understood. The aim of this study was to identify differences between individuals with current and past non-suicidal self-injury (NSSI) in a large probability sample of university students using quantitative and qualitative methods. Predictors of psychological growth related following NSSI cessation were also examined.

Method: The sample included 836 students who participated in a larger online study of well-being at eight U.S. colleges and who reported current or past history of repeated NSSI. The average age of respondents used in analysis was 21.3 years. They were $78.3 \%$ female and $21.7 \%$ male and were $70.7 \%$ Caucasian, $1.4 \%$ African American/Black, $5.5 \%$ Hispanic, $7.8 \%$ Asian/Asian American and $14.7 \%$ other. Analyses tested differences in demographics, NSSI characteristics (e.g. lifetime frequency, number of NSSI functions, NSSI disclosure), formal help-seeking, psychosocial factors, and mental health and trauma histories.

Results: Individuals with current NSSI status were more likely to be female and slightly younger, to report higher NSSI lifetime frequency, more NSSI forms and functions, thinking of themselves as a "self-injurer", and current psychological distress. Individuals with current NSSI status were less likely to report that self-injury interfered with life, that therapy was useful in stopping, perceiving social support, having a sense of meaning in life, access to more emotion regulation strategies, and life satisfaction. Qualitative data suggested that cessation may be attributable to changes in ability to regulate emotion (62.6\%), self-awareness (38.7\%), and important relationships to others (36.0 \%). Psychological growth after stopping NSSI was predicted by more severe NSSI (form and perceived NSSI dependence), having talked about NSSI with others and higher numbers of confidantes, perceived life satisfaction, and a history of suicide action.
\end{abstract}

Conclusions: These findings add to the still nascent body of literature examining processes related to NSSI cessation. Our results point to the importance of help-seeking and social support, as well as psychosocial processes in stopping NSSI.

Keywords: Non-suicidal self-injury, Young adult mental health, Psychological growth, Self-injury cessation

\footnotetext{
* Correspondence: jlw43@cornell.edu

'Bronfenbrenner Center for Translational Research, Cornell University, Ithaca, NY 14853, USA

Full list of author information is available at the end of the article
}

\section{Biomed Central}

(c) 2016 Whitlock et al. This is an Open Access article distributed under the terms of the Creative Commons Attribution License (http://creativecommons.org/licenses/by/4.0), which permits unrestricted use, distribution, and reproduction in any medium, provided the original work is properly credited. The Creative Commons Public Domain Dedication waiver (http:// creativecommons.org/publicdomain/zero/1.0/) applies to the data made available in this article, unless otherwise stated. 


\section{Introduction}

\section{NSSI prevalence, onset, and maintenance}

Non-suicidal self-injury (NSSI) is defined as the deliberate, self-inflicted destruction of body tissue without suicidal intent and for purposes not socially sanctioned [1]. NSSI is a common phenomenon, with estimated prevalence rates of $18 \%$ in adolescents [2] to $38 \%$ in young adults [3, 4]. Although most often associated with the term "cutting", self-injury includes other self-harming behaviors such as intentional carving of the skin, scratching, burning, embedding objects in skin, or swallowing toxic substances. Although the specific behaviors employed as part of NSSI are often confused with suicide, NSSI is, by definition, undertaken without suicidal intent. It does, however, indicate levels of underlying distress that, if left unmitigated, can and sometimes do result in unanticipated severe harm or fatality $[5,6]$. Moreover, NSSI is a strong risk factor for concurrent or later suicidal thoughts and behaviors [7-9] and is also often comorbid with a variety of other concerning conditions, such as disordered eating, depression, and anxiety [10-13].

Empirical study of NSSI function generally points to a complex interplay of developmental stage, history of stress or trauma, psychological distress, negative cognition (particularly low cognitive reappraisal, high counterfactual rumination, and low anticipatory rumination), negative effect, and diverting attention away from negative stimulus [14-17]. NSSI is also often reported to increase "good" feelings as well [18, 19]. Recent laboratory-based studies suggest that relief experienced when a painful stimulus is removed, called "pain offset", may underlie the observed functions [20] and may help explain why it can become habitual. Such findings underscore the complex and dynamic interplay of factors likely to contribute to NSSI maintenance and, most saliently here, cessation.

\section{NSSI cessation}

Although the body of literature contributing to understanding self-injury epidemiology, function, and treatment has grown immensely over the past decade, elucidation of key factors and pathways leading to cessation and recovery is still fairly nascent. Once started, NSSI can last for many years, though it is often cyclical with weeks, months or even years between episodes [21]. The average duration of NSSI among community populations is $2-4$ years [22]. Factors associated with NSSI cessation are not well understood. What does exist suggests that demographics, NSSI characteristics, changes in context and/or relationships, reductions in negative effect, and increases in coping capacity may play a role in facilitating cessation [23-26].

For example, in a prospective 1 year study of self-injury, individuals who reported current self-injury reported significantly greater NSSI frequency, more serious wounds, lower cognitive reappraisal, and higher emotional suppression than those who had discontinued the behavior [27]. Similarly, in a study comparing past and current individuals who self-injure, Rotolone and Martin [28] found that compared to individuals who had injured once or more in the past year, those with any self-injury history but who had not self-injured in the past year reported higher family support, self-esteem, resilience, and satisfaction with life. In a similar analysis, Brown and colleagues [23] found few differences in coping style between the past, present and no NSSI history young adults, but did find that individuals with recent self-injury experience reported greater levels of negative emotion than those who had never self-injured. In an examination of factors distinguishing past and current NSSI in high school and college populations, Taliaferro and Muehlenkamp [25] found that depressive symptoms, hopelessness, as well as history of verbal or physical abuse discriminated between the two groups. There were also differences in cessation factors between the two populations studied. For high school students, more anxiety was linked to current self-injury and among college students being non-White, having negative perceptions of one's weight, a history of dating violence, and/or a same-sex sexual experience were all associated with current self-injury.

In a sample of currently self-injuring community adolescents, Deliberto and Nock [24] examined selfreported reasons for NSSI onset and cessation and found that the most common motivation for wanting to stop was due to perception of NSSI being an unhealthy behavior. Fewer participants reported wanting to stop because of unwanted attention due to NSSI, scarring, shame over the behavior, and because NSSI upsets friends and family. Notably, adolescents who reported that they first encountered the idea to selfinjure from a friend were more likely to want to stop for social reasons.

\section{NSSI growth}

Factors which promote cessation of a negative behavior is an important line of inquiry. The concept of adversity-inspired growth, however, goes one step further in its postulation of the idea that individuals struggling with mental health challenges or other forms of adversity can, and often do, actively make use of their disorder or challenges to initiate processes of personal transformation and change [29-31]. Research in the area of growth following traumatic events [32] has paved the way for study of the ways in which persistent challenges, such as chronic physical or mental health challenges, facilitate deepening or cultivation of qualities well known to be associated with resilience, hardiness and flourishing $[33,34]$. The qualities associated with growth vary some from study to study but tend to include altered capacity to positively reframe events, self-understanding, 
hopefulness, belongingness, sense of spirituality, appreciation for life, acceptance of one's life and limitations, quality of relationships and personal strength [35-37].

Studies of growth as a result of NSSI are largely absent but the possibility that struggling with mental health challenges, such as NSSI, may produce a more robust set of experiences than suffering and disability is an area ripe for exploration. In a study of the effects of being asked sensitive questions about self-injurious experience, Whitlock, Pietrusza and Purington [38] found that while $5.2 \%$ of the self-injurious sample found reflecting on these experiences difficult, nearly half $(44.9 \%)$ reported benefits to these questions with half of these falling in the "hard but thought provoking" category. In an experimental examination of being asked sensitive questions related to NSSI, Muehlenkamp, Swenson, Batejan and Jarvi [39] found that responding to detailed questions about NSSI did not produce iatrogenic effects immediately or over the follow-up period and may have contributed to positive outcomes.

The mechanisms by which growth takes place are not well understood but tend to assume that encountering chronic adversity tends to challenge and dismantle longstanding psychological patterns or assumptions that are then replaced with new paradigms, perspectives and possibilities [31]. In addition to NSSI severity and therapeutic support linked to NSSI cessation, sharing personal or private thoughts with others may result in positive outcomes when the disclosure is met with empathy and understanding [40]. This may be particularly true when this disclosure leads to clinical treatment, since self-injurious individuals in clinical treatment are less likely to engage in suicidal behaviors, have lower numbers of hospitalizations for suicidal thoughts, and also show lower medical risk in both suicidal acts and self-injurious behaviors compared to those who are not in therapy [41].

\section{Study aims}

The current study aims to address gaps in the cessation and growth literature by comparing differences between individuals with past and current self-injury experience. Through analyses of data drawn from a representative sample of students from 8 diverse colleges and universities, this study is intended to identify factors likely to be salient in NSSI cessation. In light of the existing literature in this area, we anticipate finding differences in the past and present group in a) NSSI characteristics, b) disclosure and formal treatment, c) psychosocial characteristics and d) mental health history. In addition, we extend this analysis and add to the adversity-inspired growth literature by exploring predictors of psychological growth among respondents with past self-injury history.

\section{Methods}

\section{Sample}

The overall sample on which this study is based comes from a study from 8 colleges and universities conducted in the fall of 2006 and early winter of 2007 in the Northeast and Midwest. All but 2 are located in largely urban areas. School size and population varied considerably, ranging from fewer than 2000 undergraduates to over 11,000 undergraduates. The sample was randomly drawn by each university registrar using specialized software. Invitees were sent an e-mail containing descriptive information and a link to the survey. Response rates from each university ranged from 20 to $48 \%$, with a total of 14,372 respondents $(38.9 \%)$. The sample was representative of the overall student populations across all 8 universities in terms of ethnicity, age, and socioeconomic status (SES), although more females than males participated $(57.6 \%$ vs $41.7 \%)$. Representativeness was established by comparing study sample demographics (sex, race/ethnicity, and SES) to the student population universe from which the sample was drawn.

For the purposes of these analyses, we restricted our sample to cases for which NSSI was or had been clearly repetitive ( $>5$ lifetime incidents reported) and/ or was limited solely to scab picking or nail biting. After eliminating 12 participants from the full dataset $(n=14,372)$ whose only identified NSSI behavior was scab-picking, a total of $14.0 \%(n=2017)$ of the original sample who had practiced self-injury at least once remained. Twenty five of these reported NSSI but did not respond to selfinjury recency (e.g. how long since last injury) items so were not included in these analyses. Of the final eligible sample $(n=1992), 42.0 \%(n=836)$ reported having engaged in NSSI on 6 or more occasions and had identifiable past or present NSSI status data; a total of $58.6 \%$ $(n=490)$ had engaged in NSSI in the past year (current repeated NSSI), and $41.4 \%(n=346)$ had not engaged in NSSI in the past year and reported it somewhat or very unlikely that they would injure themselves again (past repeated NSSI).

The average age of respondents used in analysis was 21.3 years. They were $73.8 \%$ female, $26.2 \%$ male and $.8 \%$ transgendered and were $71.1 \%$ Caucasian, $2.5 \%$ African American/Black, 4.8 \% Hispanic, $8.8 \%$ Asian/Asian American and $12.8 \%$ other. Socio economic status was measured by assessed paternal education: $71.4 \%$ completed college, $13.9 \%$ some college, $11.2 \%$ high school, and $3.5 \%$ less than high school.

\section{Study design and measures}

The Survey of Student Wellbeing (SSWB) was administered via a secure Internet server and required 15-30 mins to complete. Response options and, in some cases, order of questions were randomized to avoid selection 
biases based on response ordering. The study was approved by all participating universities' Committees for Human Subjects. Multiple response enhancement strategies (e.g., incentives, follow-up reminders, personalized invitations) were employed. Links to local mental health resources were placed on the bottom of every page.

\section{NSSI characteristics}

All NSSI characteristics were assessed using the NonSuicidal Self-Injury Assessment Tool [19]. An initial screening question for NSSI, "Have you ever done any of the following with the purpose of intentionally hurting yourself?" was followed by a list of 19 NSSI behaviors (e.g., "cuts wrists, arms, legs, torso or other areas of the body " and "carves words or symbols into the skin") and an "other" option. Participants were then asked questions that assessed NSSI characteristics including but not limited to frequency, function, and age of onset. Lifetime frequency of NSSI (coded as 0, 1, 2-5, 6-20, >20) was used in these analyses. Individuals who reported using self-injury exclusively as a means of practicing or attempting suicide were classified as not having practiced NSSI. Perceived dependence on NSSI was measured using a 4 item validated subscale included in the NSSI-AT. Two single item measures assessed identification with the behavior (e.g. "I think of myself as a self-injurer") and perception of NSSI as a problem (e.g. "NSSI is a problem in my life").

\section{Current repeated versus past repeated NSSI status}

The primary discriminating variable, current repeated and past repeated self-injury status, was determined by creating two discrete categories of individuals based on NSSI lifetime frequency (only individuals with over 6 lifetime incidents of NSSI were included) and responses to a) length of time since last self-injury and, depending on the response, a follow-up item which asked about likelihood of future self-injury. Individuals who indicated that it had been a year since they last self-injured and that they were unlikely to injure again in the future were coded as "past repeated"; all others were coded as "current repeated".

\section{NSSI disclosure and help-seeking}

NSSI disclosure and formal help-seeking measures were also taken from the NSSI-AT. We included an indicator of whether or not the self-injurious respondent has had a conversation with anyone about the self-injury and, for individuals who endorsed this item, the number of such conversations and the number of helpful conversations about NSSI. We also included a set of items related to therapy and formal help-seeking. Five items that were rated on a scale of $1=$ agree to $4=$ disagree assessing attitudes toward professional help-seeking (e.g. "If I were experiencing an emotional crisis, I could find relief in counseling".) were summed to form the willingness to seek professional help scale $(\alpha=.75)$ [42]. An indicator was used for whether or not the participant had ever attended therapy for any reason: "Have you ever gone to a therapist (e.g., psychologist, psychiatrist, social worker) to talk about an issue you were having (not including family or couples' therapy)?" and, if so, and how helpful this had been in stopping NSSI behavior $(0=$ not at all helpful to 3 = very helpful).

\section{Psychosocial measures}

Psychosocial measures included a count of the number of people whom the respondent felt he or she could turn to when sad or depressed (0-16), an assessment of the quality of peer social support [43], four items adapted from the McMaster Family Assessment Device reflecting family emotional climate [44], three items linked to the meaning respondents found in life [45], the Limited Access to Emotion Regulation Strategies subscale of the Difficulties in Emotion Regulation Scale [46], and a rating of life satisfaction [47]. All of these were scored using a Likert-type response scale and showed acceptable Cronbach's alphas in this sample (.73-.92). The number of people to whom respondents turned when distressed was measured by summing endorsed responses to an item which asked, "Who do you feel comfortable getting help from when you feel anxious, sad, or depressed?" Respondents selected all that applied from a list of 23 categories that ranged from friends and parents to therapists and local providers.

\section{Mental health and life trauma measures}

The mental health and life trauma measures included items intended to measure respondents' history of trauma and mental health challenges. A count of the number of lifetime traumas (e.g., witnessing or experiencing violence, death of a loved one) was assessed with a modified version of the Life History Calendar [48]. Participants were presented with a list of 12 DSM-IV psychiatric disorders and asked to check which they believed they had suffered from, been diagnosed with, or received medication for. Disorders were summed to create the number of psychiatric conditions suffered measure. The presence of lifetime disordered eating behaviors was assessed with four yes/no items (e.g. "have you ever repeatedly severely restricted your eating?") [49]. Psychological distress over the last 30 days was measured with a modified version of the K-6 [50]; the "all of the time" response option was omitted. Consequently, continuous K-6 scores ranged from 6-24 and were used rather than categories. Reports of suicidal ideation, behaviors, and attempts were measured using a scale developed by Kessler and colleagues [51], adapted to a web-based format by including an initial screening question, "Have 
you ever seriously considered or attempted suicide?" Individuals who answered positively were asked to identify specific behaviors engaged in (including ideation), ages, and seriousness of suicide attempts made. Individuals were categorized into three groups based on the most serious level of suicide reported: no suicidal thoughts and behaviors, suicidal thoughts (including ideation, plan, or method), and suicide action (writing a suicide note or attempting suicide). Individuals who indicated that they had considered or attempted suicide but who only then selected that they were not that serious about it were included in the ideation group.

\section{Reflections on self-injury cessation and recovery}

To further explore the factors that affected self-injury cessation more deeply, we analyzed an additional openended question, "If you have stopped altogether (and are confident that you will not intentionally hurt yourself again) please describe why you stopped and what specifically helped you to stop". This question was only visible to the 346 respondents who were coded as "past NSSI". Of these, 236 responded to the open-ended item. All of these, 230 were analyzed; six were omitted due to responses considered too cryptic to be coded (e.g. "How do you know it won't happen again?").

\section{Growth effects of NSSI experience}

At the time of the SSWB administration, individuals with NSSI experience who had injured over one year previously and who indicated that they were unlikely to injure again $(n=346)$ were asked to reflect on their selfinjury experience by answering the question, "Looking back, how has your experience with intentionally hurting yourself impacted your life, both positively and negatively?" Respondents were offered 12 different dichotomously scored (yes or no) response options that reflected the kinds of responses that individuals interviewed prior to this study had given in response to a similar question. These items empirically factored into three different thematic domains, two of which factored cleanly. The current study uses the Growth scale (e.g. "In thinking/ discussing my experience around intentionally hurting myself, I have learned a lot about myself and because of it have mentally/emotionally grown;" "I am now able to help others who intentionally hurt themselves;" "Discussion of my experience around intentionally hurting myself has helped me grow closer to the people I care about"). Factor analyses were performed on the tetrachoric correlation matrix because the indicators are binary and that factor scores were derived using regression. The final reliability coefficient for the Growth scale, using Kuder-Richardson Formula 20 was .66.

\section{Statistical analysis}

All analyses were conducted in SPSS version 22 [52]. Descriptive statistics were run on all study variables by past and current self-injury status (Table 1). Logistic regression with crude odds ratios, and adjusted odds ratios (AORs) with $95 \%$ confidence intervals (CIs) were constructed to examine the multivariate relationships between repeated current and repeated past NSSI status and all independent variables while controlling for demographic variables significant in preliminary analysis: age and sex (Table 1). Linear regressions of growth scores on key study variables were computed for the repeated past NSSI group only (Table 3 ). To reduce reliance on $p$-values in determining significance [53], we include $95 \%$ confidence intervals along with all effect size coefficients in tables and use all of this information when reporting results and in the discussion section.

Qualitative data were analyzed using the constant comparative method [54] to identify salient themes and was analyzed in two waves, once to derive overarching conceptual categories and related subthemes, then to apply derived codes. The first step was conducted collaboratively and iteratively with input from all authors and the second step, application of codes to data, was conducted by two independent coders familiar with the data. Responses to the open-ended item were then analyzed by two independent coders who systematically reviewed responses and, once the initial set of observations had been reviewed, key emergent themes discussed, and coding scheme determined, thematically grouped clusters were identified and were give a primary and, if warranted secondary code. Coders agreed on all but $15 \%$ of the primary categories and subtheme assignments. Disagreements were resolved by discussion and consensus.

\section{Results}

Preliminary bivariate analysis of difference between past and current repeated self-injury participants by demographic characteristics revealed no differences except that those in the past repeated NSSI group were more likely to be female than male and were slightly but significantly older $(M=21.83$ years, $S D=3.96)$ than the current repeated NSSI group $(M=21.16$ years, $S D=$ $3.46), F(1828)=6.34, p=.012$. There were no statistically significant differences in NSSI group by race/ethnicity, father's education level (used as a proxy for socioeconomic status), and sexual orientation.

Descriptive statistics for all study variables by NSSI past and current repeated groups along with multivariate analyses controlling for sex and NSSI frequency are shown in Table 1. Of NSSI characteristics, lifetime NSSI frequency of 21-50 and more than 50 times, the number of NSSI functions, identification as someone who self- 
Table 1 Descriptive statistics and logistic regressions of past repeated NSSI on all study variables

\begin{tabular}{|c|c|c|c|c|c|}
\hline & \multicolumn{2}{|c|}{ Current repeated $^{\mathrm{a}} \mathrm{NSSI}$} & \multicolumn{2}{|c|}{ Past $^{\text {b }}$ repeated NSSI } & \multirow{2}{*}{$\begin{array}{l}\text { Multivariate model } \\
\text { AOR }[95 \% \mathrm{Cl}]\end{array}$} \\
\hline & $\mathrm{M}(\mathrm{SD})$ & $\%(n)$ & $\mathrm{M}(\mathrm{SD})$ & $\%(n)$ & \\
\hline \multicolumn{6}{|l|}{$\operatorname{Sex}^{d}$} \\
\hline Male & & $65.4(142)$ & & $34.6(75)$ & 1.00 \\
\hline Female & & $55.9(340)$ & & $44.1(268)$ & $1.55^{* *}[1.11,2.15]$ \\
\hline Age & $21.1(3.4)$ & & $21.8(3.9)$ & & $1.05^{* *}[1.01-1.1]$ \\
\hline \multicolumn{6}{|l|}{ NSSI characteristics } \\
\hline \multicolumn{6}{|l|}{ NSSI lifetime frequency } \\
\hline $6-10$ times & & $27.6(135)$ & & $38.7(134)$ & 1.00 \\
\hline 11-20 times & & $23.3(114)$ & & $27.2(94)$ & $.79[.54,1.15]$ \\
\hline $21-50$ times & & $22.7(111)$ & & $21.7(75)$ & $.60^{*}[.41, .90]$ \\
\hline$>50$ times & & $26.5(130)$ & & $12.4(43)$ & $.28^{* * *}[.18, .44]$ \\
\hline Age of NSSI onset & $14.3(3.5)$ & & $14.5(3.04)$ & & $1.01[.96,1.06]$ \\
\hline Number of NSSI functions & $6.2(3.8)$ & & $5.08(3.5)$ & & $.92^{* * *}[.88, .96]$ \\
\hline Number of NSSI forms & $3.42(2.67)$ & & $2.96(2.02)$ & & $.93 *[.88, .99]$ \\
\hline Perceived dependence on NSSI & $2.5(.99)$ & & $2.5(0.91)$ & & $.93[.60,1.09]$ \\
\hline I think of myself as a self-injurer & & $30.3(139)$ & & $19.1(62)$ & $.54^{* * *}[.38, .76]$ \\
\hline NSSI is a problem in my life & $2.38(1.38)$ & & $3.10(1.48)$ & & $1.4^{* * *}[1.27,1.57]$ \\
\hline \multicolumn{6}{|l|}{ Disclosure \& formal help-seeking } \\
\hline Have had a conversation about NSSI & & $62.1(295)$ & & $57.3(189)$ & $0.861 .01,1.09]$ \\
\hline Number of NSSI conversations ${ }^{\mathrm{e}}$ & $2.3(1.38)$ & & $2.17(1.17)$ & & $0.91[.78,1.05]$ \\
\hline Number of helpful NSSI conversations ${ }^{e}$ & $1.63(0.86)$ & & $1.98(1.10)$ & & $1.02[.95,1.1]$ \\
\hline Willingness to seek professional help & $13.09(3.62)$ & & $13.78(3.99)$ & & $1.12[.98,1.28]$ \\
\hline Ever been in therapy & & $64.2(307)$ & & $68.9(230)$ & $1.15[.85,1.56]$ \\
\hline Helpfulness of therapy in stopping NSSI ${ }^{f}$ & $1.64(0.86)$ & & $1.97(1.11)$ & & $1.45^{* * *}[1.19,1.76]$ \\
\hline \multicolumn{6}{|l|}{ Psychosocial factors } \\
\hline Number of people can turn to when distressed & $3.20(2.37)$ & & $3.43(2.29)$ & & $1.03[.97,1.10]$ \\
\hline Quality of social support & $10.42(2.02)$ & & $10.86(1.77)$ & & $1.25^{* * *}[1.10,1.41]$ \\
\hline Family emotional climate & $12.24(4.71)$ & & $12.17(4.74)$ & & $0.99[.97,1.02]$ \\
\hline Found meaning in life & $20.84(5.57)$ & & $21.95(6.38)$ & & $1.21^{* *}[1.06,1.37]$ \\
\hline Emotion regulation strategies & $26.31(7.43)$ & & $29.48(6.88)$ & & $1.39^{* * *}[1.23,1.58]$ \\
\hline Life satisfaction & $20.02(7.39)$ & & $21.91(7.37)$ & & $1.22^{* *}[1.07,1.40]$ \\
\hline \multicolumn{6}{|l|}{ Mental health and life trauma } \\
\hline Count of traumatic life events & $2.30(1.73)$ & & $2.24(1.67)$ & & $0.96[.88,1.05]$ \\
\hline Perceived suffered psychiatric condition & & $62.0(304)$ & & $69.1(239)$ & $1.29[.95,1.73]$ \\
\hline Disordered eating behaviors & & $49.8(244)$ & & $49.7(172)$ & $.96[.72,1.27]$ \\
\hline K-6 score & $15.4(3.99)$ & & $13.6(3.67)$ & & $.88^{* * *}[.85, .92]$ \\
\hline \multicolumn{6}{|l|}{ Suicidal thoughts or behaviors } \\
\hline No suicidal thoughts or behaviors & & $45.4(221)$ & & $40.8(141)$ & \\
\hline Suicidal thoughts only & & $36.4(177)$ & & $41.7(144)$ & $1.25[.92,1.7]$ \\
\hline Suicide behaviors & & $18.1(88)$ & & $17.3(60)$ & $1.1[.74,1.65]$ \\
\hline
\end{tabular}

NSSI non-suicidal self-injury, $C /$ confidence interval, $A O R$ adjusted odds ratio

${ }^{*} p<.05,{ }^{* *} p<.01,{ }^{* * *} p<.001$

arepeated indicates 6 or more lifetime NSSI episodes

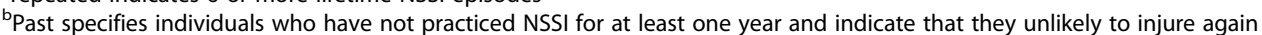

'Derived from one logistic regression model per row that controls for sex and age

${ }^{\mathrm{d}}$ Frequencies do not sum to $100 \%$ due to missing data

ef participants who had ever had a conversation about NSSI

fof participants who had ever been to therapy 
injures, and believing that NSSI is a problem predicted differences between in current and past NSSI group status. Specifically, individuals with higher NSSI lifetime frequencies were less likely to have stopped. This association appeared to be dose-dependent, with 50 or more lifetime NSSI episodes showing lower odds of stopping NSSI than lifetime frequency of 21-50. Examination of effect sizes and confidence intervals also showed that past NSSI status was predicted by fewer number of NSSI functions endorsed (AOR .92, $95 \% \mathrm{CI}, .88-.96$ ), fewer number of NSSI forms used (AOR .93, $95 \%$ CI, .88, .99), less likelihood of thinking of oneself as a self-injurer (AOR .54, $95 \%$ CI, .38-.76), and of greater acknowledgement of perceiving NSSI as a problem in one's life (AOR $1.4095 \%$ CI, 1.27-1.57). Individuals who had ceased self-injuring were also more likely than the current self-injury group to be female (AOR 1.55, $95 \%$ $\mathrm{CI}, 1.11,2.15)$ and to be slightly older than the current self-injury group (21.8 versus 21.1 years). There were no differences in age of onset or perceived dependence on NSSI between past and current NSSI groups.

Current and past NSSI status was not predicted by any of the disclosure measures, except that individuals who had stopped were more likely than their currently injuring peers to report that formal therapy was helpful in cessation (AOR 1.45, 95 \% CI, 1.19-1.76). The psychosocial measures were consistent predictors of NSSI cessation. Specifically, individuals who had stopped reported higher quality social support from peers (AOR $1.25,95 \% \mathrm{CI}, 1.10-1.41)$, more found meaning in life (AOR 1.21, $95 \% \mathrm{CI}, 1.06-1.37$ ), greater life satisfaction (AOR 1.22, $95 \% \mathrm{CI}, 1.07-1.40$ ), and more effective emotion regulation strategies (AOR 1.39, 95 \% CI, 1.231.58). The only mental health history measure that was useful in discriminating between the two groups was current psychological distress (K-6), where current NSSI status was associated with greater current (last 30 days) psychological distress.

The next analysis used comments made by individuals who have stopped self-injuring to understand factors ascribed to their successful cessation. Results of these analyses are shown in Table 2.

As a whole, respondents identified increases in emotional regulation skills as the primary driver of NSSI cessation, with $62.6 \%$ of all respondents receiving at least one emotion regulation code. Many also reported growth of self-awareness, with $38.7 \%$ of respondents receiving at least one of these codes, and $23.9 \%$ identified changes in coping skills or tools. The next largest category was in the area of relationships, with $36 \%$ of all respondents receiving at least one connections with others code, with $23.9 \%$ indicating that caring friends or loved ones were a strong factor in the decision to stop. Maturity was the third dominant theme category with $26.9 \%$ of all respondents identifying that they simply "grew out of it" in some way. Notably, despite the fact that the respondents included in these analyses had all repeatedly selfinjured, $15.7 \%$ indicated that the practice had minimal impact on their lives. Only $7.4 \%$ identified therapy as a clear factor in their cessation.

\section{Growth orientation in NSSI cessation}

The second model was designed to identify the factors among those used in the cessation analysis that predicted a growth orientation as a result of NSSI experience. This analysis was restricted to the 230 participants who met criteria for past repeated NSSI and who answered this question. A simple count of endorsed items showed that about $67 \%$ reported endorsing no growth items, $20 \%$ reporting at least one growth item, $8 \%$ reporting two growth items, and $5 \%$ reporting all three NSSI growth scale items.

The bivariate and final multivariate model controlling for all items significant in the bivariate model is reported in Table 3. Bivariate analysis suggested that, as a group, NSSI characteristics, disclosure and help seeking and psychosocial factors were most useful in predicting growth scores. Examination of effect sizes and confidence intervals showed notable effects for multiple secondary NSSI characteristics: number of lifetime incidents, number of NSSI forms and functions and perceived dependence on NSSI. Also notable were whether one has had a conversation about NSSI with someone, number of individuals one perceives e/she can turn to when anxious, sad or depressed, current life satisfaction, and having a history of suiciderelated behavior.

When all independent variables significant in the bivariate model are entered in the multivariate model, six show robust effect sizes when all parameters of interest are considered: perceived dependence on self-injury (unstd $\beta=.22$, $95 \% \mathrm{CI}=.11, .34, p<.001)$, having had a conversation with someone about NSSI (unstd $\beta=.29,95 \% \mathrm{CI}=.06, .51, p<$. 01 ), number of self-injury forms (unstd $\beta=.06,95 \%$ $\mathrm{CI}=.01, .12, p<.001$ ), number of individuals one confides in (unstd $\beta=.06,95 \% \mathrm{CI}=.01, .11, p<.01$ ), perceived life satisfaction (unstd $\beta=.15,95 \% \mathrm{CI}=.04, .25, p<.01$ ), and history of suicide-related action (unstd $\beta=.34,95 \%$ $\mathrm{CI},=.06, .63, p<.01)$. As a whole, the multivariate model explained a significant amount of the proportion of variance in growth scores, $R_{a d j .}^{2}=.21, F=13.01, p<.001$.

\section{Comment}

Understanding factors associated with NSSI cessation is a nascent but important empirical endeavor. Consistent with the small but growing body of research in this area, largely conducted with college populations [23], we find that stopping NSSI behavior is associated with a variety of factors across several domains. In general, cessation is 
Table 2 Why stop? Attribution categories, sub-themes, and examples

\begin{tabular}{|c|c|}
\hline $\begin{array}{l}\text { Category/subtheme (\% of all respondents with this } \\
\text { as a primary or secondary code) }\end{array}$ & Example \\
\hline \multicolumn{2}{|l|}{ Connection with others (36 \%) } \\
\hline \multirow[t]{2}{*}{ Positive connections $23.9 \%$} & "I entered into a loving relationship" \\
\hline & $\begin{array}{l}\text { "Some of my high school friends were really concerned about what they knew, and talking to } \\
\text { them helped a lot" }\end{array}$ \\
\hline Negative effect on cared for others $5.2 \%$ & $\begin{array}{l}\text { "I stopped because of the people that loved me at the time. I wasn't just hurting myself, but I } \\
\text { was hurting the people that cared about me. That was hard for me to understand, but once it } \\
\text { clicked I was done." }\end{array}$ \\
\hline \multirow[t]{2}{*}{ Removal of negative relationships $6.9 \%$} & "Space away from family/frustration." \\
\hline & "I moved away from the cause - my parents." \\
\hline Professional/Therapeutic Support (7.4 \%) & $\begin{array}{l}\text { "Through the program of recovery that I follow for my substance abuse problem (AA) and } \\
\text { through the assistance of my therapist/psychiatrist, I have learned that I am not alone in those } \\
\text { feelings and have been shown real solutions for the uncomfortable feelings I have." }\end{array}$ \\
\hline \multicolumn{2}{|l|}{ Emotion Regulation (62.6 \%) } \\
\hline \multirow[t]{2}{*}{ Self-awareness $38.7 \%$} & $\begin{array}{l}\text { "I also developed more of a sense of proportion: by which I mean, firstly, that I started to } \\
\text { realize that however bad I feel, it's probable that I'll feel better at some point in future, and } \\
\text { that I should the not act in ways that might permanently diminish my happiness; and } \\
\text { secondly, that my emotional distress is minor in comparison to that of many other people." }\end{array}$ \\
\hline & "I gained self-esteem and wasn't so hard on myself anymore" \\
\hline \multirow{2}{*}{$\begin{array}{l}\text { Coping skills (tools/behaviors or direct differences) } \\
23.9 \%\end{array}$} & "I realized I could cope with my emotions in less destructive ways." \\
\hline & $\begin{array}{l}\text { "I practice martial arts and work out to focus my mind, being able to spar with someone else } \\
\text { helps too." }\end{array}$ \\
\hline Life circumstances changed (10.7 \%) & $\begin{array}{l}\text { "I am happy with my life now, there is no reason for me to be nervous or scared or angry all } \\
\text { the time" }\end{array}$ \\
\hline \multicolumn{2}{|l|}{ Fear of consequences (14.2\%) } \\
\hline Environmental/Social $3.5 \%$ & $\begin{array}{l}\text { "The school made an official policy against the scars and penalized students for doing so. This } \\
\text { is when I stopped doing it." }\end{array}$ \\
\hline \multirow[t]{2}{*}{ Physical effects $10.7 \%$} & "I cut too deeply and scared myself." \\
\hline & "I don't want to have scars; they're ugly." \\
\hline \multirow[t]{2}{*}{ Maturity (26.9\%) } & "I grew out of it and realized I didn't need attention that badly." \\
\hline & "Most of it I attribute to maturing, to growing out of the raging hormones of adolescence." \\
\hline Minimal life effects (15.7\%) & $\begin{array}{l}\text { "It doesn't really matter to me that much whether I do it again or not. Now I don't ever feel } \\
\text { the need to, but I wasn't addicted and I had no serious incidents." }\end{array}$ \\
\hline
\end{tabular}

related to sex (notably, current self-injury reporters are more likely to be male than female) and, to a lesser degree, current age (past self-injury reporters are slightly older; this is probably not surprising in light of the fact that they would have had, overall, more time to stop. It is important to note, as well, that both age and number of forms show confidence intervals that suggest less than robust effects), the intensity of the NSSI, the perceived value of therapeutic and presence of social support, psychosocial characteristics and current psychological distress. The pattern of findings in the cessation analysis related to primary NSSI characteristics suggests that more entrenched self-injury practices (as measured by primary NSSI characteristics) are a key factor. Greater number of NSSI incidents, forms used, functions reported and identification as a "self-injurer" are all associated with current NSSI while greater acknowledgement of self-injury interference with life is associated with past self-injury. The role of age with regard to cessation is interesting. Although it makes sense that individuals in the cessation group would be older because they had had more time to stop, age of onset was not a factor and the statistical effects for age in the reported models is less than robust. In preliminary models, not all reported here, we also examined length of time self injuring and found that it did not contribute to cessation either. Psychosocial factors also clearly emerge as important. Feeling connected to others, possessing a broader array of emotion regulation techniques, and reporting a sense of meaning and satisfaction in life all enhance the likelihood of stopping. In terms of effect size, reporting current global psychological moderate or elevated distress is a strong predictor of current NSSI. 
Table 3 Ordinary least squares regression of growth measure on disclosure, formal help-seeking and psychosocial measures

\begin{tabular}{|c|c|c|c|c|}
\hline & \multicolumn{2}{|l|}{ Bivariate model $^{a}$} & \multicolumn{2}{|l|}{ Multivariate model $^{\mathrm{b}}$} \\
\hline & Unstd. b [95 \% Cl] & Std b & Unstd. b $[95 \%$ Cl] & Std b \\
\hline Sex, female & $0.36^{* *}[.12, .61]$ & .16 & $.13[-.17, .42]$ & .05 \\
\hline \multicolumn{5}{|l|}{ NSSI characteristics } \\
\hline NSSI lifetime frequency & $.13^{* * *}[.03, .22]$ & .14 & $-.03[-.15, .09]$ & -.03 \\
\hline Age of NSSI onset & $.03[.01, .06]$ & .09 & - & - \\
\hline Number of NSSI functions & $.07^{* * * *}[.04, .10]$ & .27 & $.01[-.03, .05]$ & .04 \\
\hline Number of NSSI forms & $.10^{* * *}[.05, .15]$ & .21 & $.08^{*}[.02, .14]$ & .20 \\
\hline Perceived dependence on NSSI & $.32^{* * *}[.20, .43]$ & .31 & $.21^{* *}[.07,34]$ & .20 \\
\hline \multicolumn{5}{|l|}{ Disclosure \& formal help-seeking } \\
\hline Have had conversation about NSSI & $.52^{* * *}[.32, .72]$ & .27 & $.25^{*}[.007, .48]$ & .12 \\
\hline Willingness to seek professional help & $.08[.00, .17]$ & .10 & - & - \\
\hline Ever been in therapy & $.18[-.04, .40]$ & .10 & - & - \\
\hline Perceived helpfulness of therapy in stopping NSSI ${ }^{c}$ & $.12[.00, .25]$ & .14 & - & - \\
\hline \multicolumn{5}{|l|}{ Psychosocial factors } \\
\hline Number of people can turn to when distressed & $.10^{* * *}[.06, .14]$ & .24 & $.07^{*}[.01, .13]$ & .12 \\
\hline Quality of social support & $.14^{* *}[.05, .24]$ & .17 & $-.004[-.08, .15]$ & -.004 \\
\hline Found meaning in life & $.17^{* *}[.05, .23]$ & .17 & $.03[-.08, .15]$ & .04 \\
\hline Life satisfaction & $.20^{* * *}[.11, .29]$ & .23 & $.15^{*}[-.02, .28]$ & .16 \\
\hline Emotion regulation strategies & $.9[-.02, .17]$ & .09 & - & - \\
\hline \multicolumn{5}{|l|}{ Mental health history } \\
\hline Count of traumatic events & $.05[-.02, .11]$ & .14 & - & - \\
\hline Number of perceived psychiatric conditions & $.14[-.09, .36]$ & .07 & - & - \\
\hline Disordered eating behaviors & $.07[-.14, .27]$ & .04 & - & - \\
\hline Psychological distress in past 30 days (K-6) & $-.02[-.05, .01]$ & -.08 & - & - \\
\hline Suicide thoughts and behaviors & - & - & - & - \\
\hline Suicidal thoughts & $.12^{*}[-.09, .34]$ & .06 & $.17[-.9, .43]$ & .09 \\
\hline Suicide behaviors & $.50^{* * *}[.23, .77]$ & .20 & $.37^{*}[.07, .68]$ & .15 \\
\hline
\end{tabular}

NSSI non-suicidal self-injury

${ }^{*} p<.05,{ }^{* *} p<.01,{ }^{* * *} p<.001$

aDerived from one ordinary least squares (OLS) regression model for each predictor

${ }^{b}$ Derived from one OLS regression model with all significant bivariate predictors included

'Of participants who had ever been to therapy

Qualitative exploration of a question designed to assess how individuals with past NSSI experience understood why they stopped generally reinforce the quantitative findings. Interestingly, participants talked largely about what they perceived changed in their lives over time to support cessation. In line with the quantitative analyses, they identified a) acquisition of emotion regulation strategies $(62.6 \%)$, b) positive connections with others (36\%), c) general "maturity" (26.9\%), d) fear of consequences $(14.2 \%)$, e) general changes in life circumstances $(10.7 \%)$, and $\mathrm{f}$ ) professional therapeutic support (7.4\%). Just over $15 \%$ responded that stopping was easy because it was not a big part of their lives to begin with. We find it notable that, as with the quantitative findings, formal therapy was a factor but not a leading identified element of cessation; more salient seem to be enhanced self-awareness and emotion regulation skill acquisition coupled with changes in contextual factors.

Although research on self-injury cessation is scarce, our findings are consistent with other studies of cessation. For example, in a multi-wave longitudinal study of self-harm over time, Moran and colleagues [55] found that natural developmental processes (what is referred to as "maturity" here) play an important role in the cessation process. Similarly, other studies have identified the role of NSSI severity as a factor contributing negatively to cessation (e.g. more frequent and physically deleterious NSSI; [27]). The current study reinforces the role of NSSI severity and also suggests that number of NSSI forms and functions also play an important role. This and other studies [25] also find that higher psychological distress is also an impediment to NSSI cessation. 
The role of psychosocial variables is more nuanced. Taken as a whole, these findings suggest that individuals who successfully cease NSSI behavior may do so because they develop higher-order reflective cognitive and emotional capacities. In their investigation of the role of emotion and coping in NSSI cessation, Brown and colleagues [23] did not find significant differences in coping skills, per se, between past and presently self-injuring participants but did find differences in perceived levels of negative emotion. Rotolone and Martin [28] documented differences in perceived family support, selfesteem, resilience, and satisfaction with life. Tatnell et al. [26] found that a combination of intrapersonal and interpersonal factors contributed to cessation, with capacity for cognitive reappraisal playing a significant role. In the current study, both emotions and emotion-linked perceptions (cognitions) were important. For example, cessation was not predicted by engagement in therapy, but generally being open to therapy and, more specifically, viewing one's personal therapy positively. Similarly, self-injurious individuals who had stopped were also more likely to perceive NSSI as a problem in their lives, and to have found a sense of meaning and life satisfaction. They were also likely to report more diverse strategies for managing difficult emotions than their currently self-injurious peers. Interestingly, although those who had stopped identified emotional regulation as a key area of change in the qualitative data, they were more likely to talk about enhanced self-awareness rather than the adopting of new coping skills in particular. Notably, over a quarter of respondents in the current study identified natural processes associated with maturity in cessation but age of onset did not contribute to explaining the difference between the current and cessation NSSI group. This suggests that drivers of change may be closely linked to the development of new cognitions, emotion and emotional regulation processes in ways that are not linked exclusively to age.

Extant literature also identifies social/contextual factors as important for NSSI cessation. In a study of adolescent advice for teen NSSI cessation, Berger, Hasking, and Martin [56] found that having non-judgmental parents and teachers to talk to was related to improvements in parent-child relationships, referrals to professionals, and reduced school pressures. Tatnelll et al. [26] found family support to a critical factor in cessation. Findings from the current study, however, suggest that enhanced emotional and social awareness and skill and an increased willingness to make use of social supports such as therapy and loved ones, may also be relevant to NSSI cessation. For example, while our respondents qualitatively identified connections with others as the single most powerful contributor to cessation, the quantitative results suggest that it is not the mere availability of others or supportive contexts that matter, but rather the ability to positively perceive and make use of these connections that matters most. It is worth noting that rates of NSSI disclosure are quite variable. Between $31 \%$ and $89 \%$ of adolescent NSSI samples report disclosing their self-injurious behavior to someone $[3,57]$ and this is most often peers [58-60]. Despite the reliance on peers, respondents tend to rate conversations with friends as less helpful than conversations with parents or other adults [61] suggesting that while confiding in someone is important, confiding in an adult capable may be most important.

The current study also was designed to extend our understanding of NSSI cessation beyond the process of stopping and into the after effects of repeated selfinjurious experiences. Toward this end, we examined respondent scores on a measure of psychological growth as a result of self-injury. This scale was intended to measure the perceived effects of NSSI experience, following cessation, along a dimension of perceived growth as a person and utility in helping others. Findings from this aspect of the study suggested that approximately one-third (33\%) of the past self-injury sample perceived any benefit to the experience with $5 \%$ indicating growth in all areas measured. Examination of the factors that explained variation in growth in the final multivariate included six key factors: number of NSSI forms, degree of perceived dependence on NSSI, conversations with others about NSSI experience, number of confidantes one can turn to when distressed, experience with suicide-behavior (beyond suicidal ideation), and sense of current life satisfaction. Of note, conversations with others about NSSI experience, having felt a high dependence on NSSI, and experience with suicide-behavior were the most powerful predictors of growth which suggests that there may be something in the very intensity of adversity coupled with the benefits of processing difficult experiences with others that contributes to a growth orientation. Isolating other important contributors, such as personality and temperament factors, optimism/pessimism and/or fixed versus flexible cognitive orientation would be a welcome extension to this line of inquiry and may contain useful implications for intervention and treatment.

\section{Implications}

The current analyses are unique in their objective and approach and contribute to the fledgling body of knowledge describing the particularities of NSSI cessation. They are also unique in their contribution to understanding factors that facilitate a growth orientation among those with a history of NSSI. They are not, however, without limitations. While we were able to capitalize on the sample size and power for analyses, our 
ability to accurately account for temporal factors in the processes of interest was limited. As such, although the sample size permits more comprehensive analyses, the comparisons in these data are drawn from one time point and based on retrospective data (current versus past NSSI history). Similarly, self-injury is very cyclical and people may stop for long periods of time and then start again. Our decision to designate the cessation group as individuals who had stopped for a year or more and who reported themselves not very likely to self injure again may more accurately reflect cessation intention then full recovery. Future studies may include using a longer cessation, such as three years, as a more absolute marker of recovery. Lastly, the current study was primarily conducted in a college population and may not be generalizable to other populations.

The fact that the number of NSSI functions endorsed and current psychological distress differentiated past and present repeated self-injury suggests that the magnitude of reliance on the behavior may supersede the particular function in predicting cessation capacity. Potentially mutable indicators are those related to enhanced selfawareness: acknowledging that NSSI is a problem and NSSI as a factor contributing to a sense of meaning and satisfaction in life. Interestingly, satisfaction in life is also a factor in predicting psychological growth as is reporting higher numbers of social confidants and support. The fact that psychological growth was also predicted by greater levels of NSSI dependence while injuring as well as by a history of suicide behaviors also lends credibility to the idea that enhanced self-awareness and social support may be primary factors in the recovery and growth process.

Making and maintaining connections to others, through a willingness to seek and actively use therapy (in the case of cessation) as well as an openness to talking to others about NSSI and confiding in multiple others when distressed, is another clearly important factor in the cessation and growth process. What predicts help-seeking, however, is less clear. Help-seeking is positively associated with the frequency of NSSI [59]; however, adolescents and young adults with only one occurrence of NSSI are more likely to engage in helpseeking than those with recurrent incidents $[62,63]$. Secondary characteristics, such as individual perception that NSSI is a problem, also play a role. Fortune, Sinclair, and Hawton [64] found, for example, that perception of the behavior in the moment (i.e., premeditated or spur of the moment), motivation to act, perception that something can and should be done, and desire for help all differentiated help-seeking from non-help seeking. Other factors that contribute to help-seeking include knowledge of NSSI as a phenomenon, becoming consciousness of being in need of help, and the support of peers, friends, and family [65]. Adolescents also report that significant barriers to help-seeking included embarrassment and perceived stigma, poor mental health literacy and problems identifying behaviors as harmful, along with the preference for self-reliance [65].

In conclusion, more work is needed to better understand factors associated with NSSI cessation and growth. We find NSSI cessation to be associated with a variety of factors across several psychosocial domains. Future research should examine these processes longitudinally in order to better inform prevention and intervention efforts.

\section{Abbreviations}

NSSI: (non-suicidal self-injury), recovery, growth, NSSI cessation.

\section{Competing interests}

The authors declare that they have no competing interests.

\section{Authors' contributions}

JW conceptualized the study and lead data collection and analyses. KP contributed to the review of the literature, data coding for Table 2, framing of specific research questions, and manuscript editing. CP contributed to framing of the research questions, qualitative data analyses, analyses, and manuscript editing. All authors read and approved the final manuscript.

\section{Acknowledgements}

The authors would like to thank Elise Paul and Xing Zhang for their contributions to preliminary analyses in this paper.

\section{Author details}

${ }^{1}$ Bronfenbrenner Center for Translational Research, Cornell University, Ithaca, NY 14853, USA. ²Department of Psychology, Cornell University, Ithaca, NY, USA. ${ }^{3}$ Department of Clinical Psychology, Duquesne University, Pittsburgh, PA, USA.

Received: 12 March 2015 Accepted: 29 May 2015

Published online: 08 July 2015

\section{References}

1. International Society for the Study of Self-Injury. Definitional issues surrounding our understanding of self-injury. 2007. http://itriples.org/self-injury/ fast-facts/. Accessed May 21, 2015.

2. Muehlenkamp JJ, Claes L, Havertape L, Plener PL. International prevalence of adolescent non-suicidal self-injury and deliberate self-harm. Child Adolesc Psychiatry Ment Health. 2012;6:10.

3. Whitlock J, Muehlenkamp J, Purington A, Eckenrode J, Barreira P, Abrams $\mathrm{GB}$, et al. Non-suicidal self-injury in a college population: general trends and sex differences. J Am Coll Health. 2011;59:691-8.

4. Heath NL, Toste JR, Nedecheva T, Charlebois A. An examination of nonsuicidal self-injury among college students. J Ment Health Couns. 2008;30:137-56.

5. Andover MS, Morris BW, Wren A, Bruzzese ME. The co-occurrence of nonsuicidal self-injury and attempted suicide among adolescents: distinguishing risk factors and psychosocial correlates. Child Adolesc Psychiatry Ment Health. 2012;6:11.

6. Whitlock J, Knox KL. The relationship between self-injurious behavior and suicide in a young adult population. Arch Pediatr Adolesc Med. 2007;161:634-40.

7. Joiner TE, Ribeiro JD, Silva C. Nonsuicidal self-injury, suicidal behavior, and their co-occurrence as viewed through the lens of the interpersonal theory of suicide. Curr Dir Psychol Sci. 2012;21:342-7.

8. Whitlock J, Muehlenkamp J, Eckenrode J, Purington A, Abrams GB, Barreira $P$, et al. Nonsuicidal self-injury as a gateway to suicide in young adults. J Adolesc Health. 2013;52:486-92.

9. Wilkinson P, Kelvin R, Roberts C, Dubicka B, Goodyer I. Clinical and psychosocial predictors of suicide attempts and nonsuicidal self-injury in 
the adolescent depression antidepressants and psychotherapy trial (ADAPT). Am J Psychiatry. 2011;168:495-501.

10. Claes $L$, Vandereycken $W$, Vertommen $H$. Personality traits in eating-disordered patients with and without self-injurious behaviors. J Pers Disord. 2004;18:399-404.

11. Hankin BL, Abela JRZ. Nonsuicidal self-injury in adolescence: Prospective rates and risk factors in a $2 \frac{1}{2} 2$ year longitudinal study. Psychiatry Res. 2011;186:65-70,

12. Klonsky ED, Oltmanns TF, Turkheimer E. Deliberate self-harm in a nonclinical population: prevalence and psychological correlates. Am J Psychiatry. 2003:160:1501-8.

13. Muehlenkamp J, Gutierrez PM. Risk for suicide attempts among adolescents who engage in non-suicidal self-injury. Arch Suicide Res. 2007;11:69-82.

14. Voon $\mathrm{D}$, Hasking $\mathrm{P}$, Martin $\mathrm{G}$. The roles of emotion regulation and ruminative thoughts in non-suicidal self-injury. Br J Clin Psychol. 2014;53:95-113.

15. Andover MS, Pepper CM, Gibb BE. Self-mutilation and coping strategies in a college sample. Suicide Life Threat Behav. 2007;37:238-43.

16. Klonsky ED. Non-suicidal self-injury: an introduction. J Clin Psychol. 2007;63:1039-43.

17. Nock MK, Prinstein MJ. Contextual features and behavioral functions of self-mutilation among adolescents. J Abnorm Psychol. 2005;114:140-6.

18. Klonsky ED. The functions of self-injury in young adults who cut themselves: clarifying the evidence for affect-regulation. Psychiatry Res. 2009:166:260-8.

19. Whitlock JL, Exner-Cortens D, Purington A. Validity and reliability of the non-suicidal self-injury assessment test (NSSI-AT). Psychol Assess. 2014;26:935-46

20. Franklin JC, Lee KM, Hanna EK, Prinstein MJ. Feeling worse to feel better: pain offset simultaneously stimulates positive affect and diminishes negative affect. Psychol Sci. 2013;24:521-9.

21. Walsh BW. Treating self-injury: a practical guide. 2nd ed. New York: Guilford Press; 2012.

22. Whitlock J, Selekman M. Non-suicidal self-injury across the lifespan. Oxford handbook of suicide and self-injury. Oxford University Press; 2014

23. Brown SA, Williams K, Collins A. Past and recent deliberate self-harm: emotion and coping strategy differences. J Clin Psychol. 2007;63:791-803.

24. Deliberto T, Nock M. An exploratory study of correlates, onset, and offset of non-suicidal self-injury. Arch Suicide Res. 2008;12:219-31.

25. Taliaferro $L A$, Muehlenkamp JJ. Risk and protective factors that distinguish adolescents who attempt suicide from those who only consider suicide in the past year. Suicid Life Threat Behav. 2014;44:6-22.

26. Tatnell R, Kelada L, Hasking P, Martin G. Longitudinal analysis of adolescent NSSI: the role of intrapersonal and interpersonal factors. J Abnorm Child Psychol. 2014;46(6):885-96.

27. Andrews T, Martin G, Hasking P, Page A. Predictors of continuation and cessation of nonsuicidal self-injury. J Adolesc Health. 2013;53:40-6.

28. Rotolone C, Martin G. Giving up self-injury: a comparison of everyday social and personal resources in past versus current self-injurers. Arch Suicide Res 2012;16:147-58.

29. Cloninger CR. The science of well-being: an integrated approach to mental health and its disorders. World Psychiatry. 2006;5:71-6.

30. Roe D, Chopra M. Beyond coping with mental illness: toward personal growth. Am J Orthopsychiatry. 2003;73:334-44.

31. Roepke AM, Seligman ME. Doors opening: a mechanism for growth after adversity. J Posit Psychol. 2015;10:107-15.

32. Bonanno GA. Loss, trauma, and human resilience: have we underestimated the human capacity to thrive after extremely adverse events? Am Psychol. 2014;59:20-8.

33. O'Rourke J, Tallman B, Altmaier E. Measuring post-traumatic changes in spirituality/religiosity. Ment Health Relig Cult. 2008;11:719-28.

34. McMillen JC. Better for it: how people benefit from adversity. Soc Work. 2009;44:455-68.

35. Calhoun LG, Tedeschi RG. Handbook of post- traumatic growth: research and practice. Mahwah: Erlbaum; 2006.

36. Joseph S, Linley PA. Positive adjustment to threatning events: an organismic valuing theory of growth through adversity. Rev Gen Psychol. 2005;9:262-80.

37. Zoellner T, Maercker A. Posttraumatic growth in clinical psychology - a critical review and introduction of a two component model. Clin Psychol Rev. 2006;26(5):626-53.

38. Whitlock J, Pietrusza C, Purington A. Young adult respondent experiences of disclosing self-injury, suicide-related behavior, and psychological distress in a web-based survey. Arch Suicide Res. 2013;17:20-32.
39. Muehlenkamp JJ, Swenson LP, Batejan KL, Jarvi SM. Emotional and behavioral effects of participating in an online study of nonsuicidal self-injury: an experimental analysis. Clin Psychol Sci. 2014;3:26-37.

40. Everill J, Waller G. Disclosure of sexual abuse and psychological adjustment in female undergraduates. Child Abuse Negl. 1995;19:93-100.

41. Linehan MM, Comtois KA, Murray AM, Brown MZ, Gallop RJ, Heard HL, et al. Two-year randomized controlled trial and follow-up of dialectical behavior therapy vs therapy by experts for suicidal behaviors and borderline personality disorder. Arch Gen Psychiatry. 2006;63:757-66.

42. Fischer EH, Turner JLB. Orientations to seeking professional help - development and research utility of an attitude scale. J Consult Clin Psychol. 1970;35:79-90.

43. Hughes ME, Waite LJ, Hawkley LC, Cacioppo JT. A short scale for measuring loneliness in large surveys: results from two population-based studies. Res Aging. 2004;26:655-72

44. Epstein NB, Baldwin LM, Bishop DS. The McMaster family assessment device. J Marital Fam Ther. 1983;9.

45. Steger MF, Frazier P, Oishi S, Kaler M. The meaning in life questionnaire: assessing the presence of and search for meaning in life. J Couns Psychol. 2006;53:80-93.

46. Gratz KL, Roemer L. Multidimensional assessment of emotion regulation and dysregulation: development, factor structure, and initial validation of the difficulties in emotion regulation Scale. J Psychopathol Behav Assess. 2004;26:41-54.

47. Diener E, Emmons RA, Larsen RJ, Griffin S. The satisfaction with life scale. J Pers Assess. 1985;49.

48. Caspi A, Moffitt TE, Thornton A, Freedman D, Amell JW, Harrington H, et al. The life history calendar: a research and clinical assessment method for collecting retrospective event-history data. Int J Methods Psychiatr Res. 1996;6:101-14.

49. Stice E, Telch CF, Rizvi SL. Development and validation of the eating disorder diagnostic scale: a brief self-report measure of anorexia, bulimia, and binge-eating disorder. Psychol Assess. 2000;12.

50. Kessler RC, Andrews G, Colpe LJ, Hiripi E, Mroczek DK, Normand ST, et al. Short screening scales to monitor population prevalences and trends in non-specific psychological distress. Psychol Med. 2002;32:959-76.

51. Kessler RC, Berglund P, Demler O, Jin R, Merikangas KR, Walters EE. Lifetime prevalence and age-of-onset distributions of DSM-IV disorders in the national comorbidity survey replication. Arch Gen Psychiatry. 2005;62:593-602.

52. IBM Corp. IBM SPSS statistics for windows, version 22.0. Armonk: IBM Corp; 2013.

53. Sullivan GM, Feinn R. Using effect size-or why the $P$ value is not enough. J Grad Med Educ. 2012;4:279-82.

54. Glaser B, Strauss A. The discovery of grounded theory. Hawthorne: Aldine Publishing Company; 1967.

55. Moran P, Coffey C, Romaniuk H, Olsson C, Borschmann R, Carlin JB, et al. The natural history of self-harm from adolescence to young adulthood: a population-based cohort study. Lancet. 2012;379:236-43.

56. Berger E, Hasking P, Martin G. 'Listen to them': adolescents' views on helping young people who self-injure. J Adolesc. 2013;36:935-45.

57. Muehlenkamp J, Brausch A, Quigley K, Whitlock J. Interpersonal features and functions of nonsuicidal self-injury. Suicide Life Threat Behav. 2013;43:67-80.

58. Heath NL, Ross S, Toste JR, Charlebois A, Nedecheva T. Retrospective analysis of social factors and nonsuicidal self-injury among young adults. Can J Behav Sci. 2009:41:180-6.

59. Nixon MK, Cloutier P, Jansson SM. Nonsuicidal self-harm in youth: a population-based survey. Can Med Assoc J. 2008;178:306-12.

60. Willcox HC, Arria AM, Caldeira KM, Vincent KB, Pinchevsky GM, O'Grady KE. Longitudinal predictors of past-year non-suicidal self-injury and motives among college students. Psychol Med. 2012:42:717-26.

61. Pietrusza C, Rothenberg P, Whitlsock J. Reaching out: the role of disclosure and support on non-suicidal self-injury cessation. Poster presented at International Society for Study of Self-Injury 6th annual conference. New York; 2011.

62. Evans E, Hawton K, Rodham K. Suicidal phenomena and abuse in adolescents: a review of epidemiological studies. Child Abuse Negl. 2005;29:45-58

63. Whitlock J, Eckenrode J, Silverman D. Self-injurious behaviors in a college population. Pediatrics. 2006;117:1939-48

64. Fortune S, Sinclair J, Hawton K. Help-seeking before and after episodes of self-harm: a descriptive study in school pupils in England. BMC Public Health. 2008:8

65. Rissanen ML, Kylma J, Laukkanen E. Descriptions of help by Finnish adolescents who self-mutilate. J Child Adolesc Psychiatr Nurs. 2009;22:7-15. 